\title{
Bacteremia por Rhodococcus equi em paciente com síndrome da imunodeficiência adquirida: relato de caso
}

\author{
Bacteremia due to Rhodococcus equi in a patient with \\ acquired immunodeficiency syndrome: case report
}

\author{
Carina Secchi ${ }^{1,2}$, Fabiana Pereira ${ }^{1}$, Leandro Reus Rodrigues Perez ${ }^{2}$, \\ Pedro Alves d'Azevedo² e Silvia da Silva Rios ${ }^{3}$
}

\begin{abstract}
RESUMO
Rhodococcus equi é um importante agente de infecções zoonóticas, podendo causar sérias infecções em humanos, principalmente em pacientes imunocomprometidos. Neste estudo, nós relatamos o caso de uma bacteremia fatal devido a Rhodococcus equi em paciente com síndrome da imunodeficiência adquirida (HIV positivo).
\end{abstract}

Palavras-chaves: Rhodococcus equi. Bacteremia. Imunocomprometidos. HIV.

\begin{abstract}
Rhodococcus equi is an important agent for zoonotic infections, and may cause serious infections in humans, especially immunocompromised patients. In this study, a case of fatal bacteremia due to Rhodococcus equi in a patient with acquired immunodeficiency syndrome (HIV positive) is reported.
\end{abstract}

Key-words: Rhodococcus equi. Bacteremia. Immunocompromised. HIV.

O Rhodococcus equi (R. equi) é reconhecido como um microrganismo intracelular facultativo, ubíquo, de caráter oportunista, associado as diferentes afecções no homem e animais. É um cocobacilo pleomórfico, Gram-positivo, aeróbio, parcialmente ácido-resistente, não formador de esporos, imóvel e amplamente distribuído na natureza. Foi primariamente relatado em infecções zoonóticas em 1923, em eqüinos que apresentaram pneumonia granulomatosa crônica' ${ }^{5}$ o primeiro caso em humanos foi relatado em 1967 em paciente com abscesso pulmonar $^{3}$, desde então muitos casos foram descritos na literatura ${ }^{18}$. No homem, a rodococose é apontada como doença emergente, freqüentemente relacionada a indivíduos severamente comprometidos, incluindo pacientes convalescentes de transplantes, com neoplasias malignas, sob terapia imunossupressiva ou em alcoólatras. Em anos recentes, grande parte da casuística de infecções humanas pelo $R$. equi tem sido relatada em pessoas acometidas pela síndrome da imunodeficiência adquirida (HIV positivos) ou mesmo em pessoas saudáveis ${ }^{17}$. A mortalidade, associada à infecção, varia segundo a condição do hospedeiro, sendo de aproximadamente $11 \%$ em imunocompetentes, 20 a $25 \%$ em pacientes imunocomprometidos não-HIV e 50 a $55 \%$ em pacientes HIV positivos (AIDS) ${ }^{7}$. A transmissão do R. equi, para o homem, deriva da exposição ao agente no ambiente, geralmente secundária a lesões transcutâneas, ou do contato recente com animais, principalmente equiinos ${ }^{16}$. Pode causar infecções pulmonares, feridas, abscessos, peritonite, meningite, pericardite, osteomielite, entre outras. 0 início da doença pode ser insidioso e com características semelhantes ao observado para os gêneros Mycobacterium, Actinomyces e Nocardia ${ }^{2}$.

Determinados fatores de virulência conferem ao $R$. equi mecanismos de evasão do sistema imune, possibilitando ao microrganismo multiplicar-se no interior de fagócitos, como neutrófilos e macrófagos, dificultando assim o estabelecimento de resposta imune adequada e induzindo lesões do tipo piogranulomatosa ${ }^{7}$. Esse tipo especial de inflamação na rodococose leva a processos de difícil resolução tecidual, refratários à terapia antimicrobiana convencional ${ }^{2}{ }^{10}$.

\footnotetext{
1. Weinmann Laboratório, Porto Alegre, RS. 2. Programa de Pós-Graduação em Ciências Médicas da Fundação Faculdade Federal de Ciências Médicas de Porto Alegre, Porto Alegre, RS. 3. Grupo Hospitalar Nossa Senhora da Conceição, Porto Alegre, RS.

Endereço para correspondência: Dra. Carina Secchi. Weinmann Laboratório. Rua Ramiro Barcellos 910, $5^{\circ}$ andar, $90035-001$ Porto Alegre, RS. Tel: $55513314-3838$

e-mail: csecchi@weinmann.com.br

Recebido para publicação em 30/1/2006

Aceito em 4/12/2006
} 
Considerando a disseminação hematogênica, o $R$. equi pode infectar qualquer órgão, mas, o pulmão é afetado com maior freqüência, apresentando algum comprometimento em 80 $97 \%$ dos pacientes imunocomprometidos e em torno de $40 \%$ em imunocompetentes ${ }^{7}$. As limitações do sucesso terapêutico nas infecções por RRhodococcus equi, no homem e em animais, fundamentado na utilização de antimicrobianos, têm motivado diferentes estudos de suscetibilidade do agente, ensaios com novas drogas e suas associações. A refratariedade do agente à terapia antimicrobiana convencional decorre do desenvolvimento de resistência natural (simples ou múltipla), de resistência adquirida ao longo da terapia, da descontinuidade do tratamento ou da limitação de certas drogas ao acesso intracelular e/ou do foco piogranulomatoso. Os diferentes estudos conduzidos na investigação da suscetibilidade do $R$. equi, de origem animal, apontam que as drogas de maior efetividade, in vitro, incluem antimicrobianos do grupo dos macrolídeos (eritromicina), quinolonas (enrofloxacina, ciprofloxacina), aminoglicosídeos (gentamicina, neomicina, amicacina), cefalosporinas, vancomicina, imipenem e rifampicina, além de associações, como a rifampicina e eritromicina, considerada de eleição no tratamento de infecções causadas pelo $R$. equi ${ }^{6}{ }^{10}$.

\section{RELATO DE CASO}

Paciente masculino de 34 anos, internado no serviço de Infectologia do Hospital Nossa Senhora da Conceição de Porto Alegre, RS, com queixa de perda ponderal, astenia, febre e icterícia há 30 dias. Vinha fazendo uso da associação RHZ (rifampicina, isoniazida e pirazinamida) há duas semanas devido a diagnóstico preliminar de tuberculose pulmonar realizado em posto de saúde na capital. Apresentava lesões ulceradas de pele há, aproximadamente um mês. Foram solicitadas hemoculturas e biópsia de pele, bem como outros exames laboratoriais complementares como hemograma com resultados de: $8,9 \mathrm{~g} / \mathrm{dL}$ de hemoglobina, $27 \%$ de hematócrito, 5.200 leucócitos/ $\mu \mathrm{L}$ e diferencial (6\% de bastões, $86,5 \%$ de segmentados, $0,5 \%$ de basófilos e 3,6\% de linfócitos). 0 resultado do teste anti-HIV foi positivo (Abbott, Illinois, USA) com CD4+ 1 célula/mL e carga viral de 112.194 cópias/mL. Apresentava látex criptocócico (IMMY, Norman, USA) nãoreagente no sangue, anti-HCV (Abbott, Illinois, USA) nãoreagente e pesquisa para bacilo álcool-resistente (BAAR) negativo no escarro. Também, foram realizados outros exames complementares como Raios-X de tórax com ampla lesão cavitada no lobo inferior direito e ecografia abdominal com aumento do fígado e baço. Os frascos de hemocultura positivos foram enviados ao Weinmann Laboratório, setores de Bacteriologia/Biologia Molecular para identificação de bacilos Gram-positivos com ramificações. Resultados 0 microrganismo observado pela coloração de Gram, a partir dos frascos de hemocultura com crescimento, foi um bacilo Gram-positivo com ramificações e com coloração de ZiehlNeelsen negativa para bacilos álcool-ácido resistente (BAAR).
A amostra de sangue foi semeada em agar-sangue de carneiro (bioMérieux, Marcy l'Etoile, France) incubado a $35^{\circ} \mathrm{C}$ em microaerofilia e em anaerobiose por aproximadamente 48 horas. Após incubação, houve crescimento em aerobiose de colônias lisas, irregulares, brilhosas, mucóides que com 0 passar do tempo adquiriram cor vermelho-alaranjado. A coloração de Gram, a partir das colônias, revelou cocobacilos Gram-positivos. Testes adicionais foram realizados como a prova da oxidase (negativa), da urease (positiva) e teste de suscetibilidade aos antimicrobianos. 0 microrganismo foi submetido também ao sistema automatizado VITEK, cartão GPI (bioMérieux, Marcy l'Etoile, France), que não identificou a bactéria e ao kit API Coryne (bioMérieux, Marcy l'Etoile, France) cujos resultados de algumas provas foram duvidosos, não possibilitando uma correta identificação. Posteriormente, a identificação da bactéria foi realizada pela técnica da reação da polimerase em cadeia (PCR) através da amplificação do gene $16 \mathrm{~S}$ rRNA (ca. $1.500 \mathrm{bp}$ ) utilizando primers 285 e $261^{4}$. Os produtos do PCR obtidos com diferentes primers foram purificados e as primeiras 500 bases determinadas pelo seqüenciamento utilizando o primers $16 \mathrm{~S}$ (5' TATTACCGCRGCTGCTGG - 3') e o kit BigDye Terminator (Applied Biosystems, Foster City, USA), conforme instruções do fabricante.

\section{DISCUSSÃO}

Rhodococcus equi é um patógeno oportunista emergente, especialmente em pacientes infectados pela síndrome da imunodeficiência adquirida, conforme paciente relatado neste caso. Outros problemas relatados neste paciente foram: pneumonia cavitada, hepatite medicamentosa ao RHZ e lesões de pele que foram identificadas como Paracoccidiodes brasiliensis. Como tratamento, o paciente recebeu benzilpenicilina potássica, oxacilina e anfotericina B, mas seu quadro evoluiu a óbito.

Rhodococcus equi é usualmente suscetível a eritromicina, ciprofloxacina, vancomicina, aminoglicosídeos, rifampicina, carbapenêmicos, embora o organismo pareça suscetível aos $\beta$-lactâmicos in vitro, estudos demonstram resistência adquirida durante o tratamento com estas drogas. No teste realizado no laboratório o microrganismo apresentou concordância com a literatura: suscetibilidade aos antimicrobianos acima citados e resistência aos $\beta$-lactâmicos (teste de suscetibilidade nãopadronizado). A diferenciação clínica de lesões pulmonares com micobacterioses e nocardioses deve envolver também a suspeita de $R$. equi, como também laboratorialmente entre difteróides e outros microrganismos álcool-ácido-resistentes a fim de realizar a correta identificação do germe para melhor escolha dos antimicrobianos já que $R$. equi apresenta alta taxa de mortalidade.

Rhodococcus equi deve ser suspeitado em pacientes imunocomprometidos ou HIV positivos que apresentam infecção respiratória de curso não-habitual (pneumonia lentamente evolutiva $)^{9}$. É importante o estudo da suscetibilidade aos antimicrobianos para o correto manejo do paciente, visto que, em geral, o tratamento específico desta infecção é prolongado. 


\section{AGRADECIMENTOS}

Os autores desejam agradecer aos médicos, Renato Cassol F. da Silva e Teresinha Joana Dossin, ao serviço de Controle de Infecção e ao Laboratório de Bacteriologia do Grupo Hospitalar Conceição, pelo envio da amostra e dados do paciente relatado nesse caso.

\section{REFERÊNCIAS BIBLIOGRÁFICAS}

1. Barsotti M, Cupisti A, Morelli E, Meola M, Barsotti G. Sepsis from Rhodococcus equi successfully treated in a kidney transplant recipient. Nephrology Dialysis Transplantation 12:2002-2004, 1997.

2. Brown JM, MacNeil MM. Nocardia, Rhodococcus, Gordonia, Actinomadura, Streptomyces, and other Aerobic Actinomycetes. In: Murray P, Baron EJ, Jorgensen JH, Pfaller MA, Yolken RH (eds) Manual of Clinical Microbiology $8^{\text {th }}$ edition, American Society of Microbiology, Washington DC, p.502-531, 2003.

3. Golub B, Falk G, Spink WW. Lung abscess due to Corynebacterium equi: report of the first human infection. Annals Internal Medicine 66: 1174-11747, 1967.

4. Kirschner P, Meier A, Böttger EC. Genotypic identification and detection of mycobacteria - facing novel and uncultured pathogens.
In: Persing DH, Smith TF, Tenover FC, White TJ (eds) Diagnostic molecular microbiology principles and applications. American Society for Microbiology, Washington. p.173-190, 1993.

5. Magnusson H. Pneumonie beim Fohlen Ein neuer Eitererreger beim Pferd. Archiv fur Wissenschaftliche und Praktische Tierheilkunde 50:22-37, 1923.

6. Napoleão F, Damasco PV, Ferreira TC, Camello TCF, Vale MD, Andrade AFB, Hirata R, Guaraldi ALM. Pyogenic Liver abscess due to Rhodococcus equi in an Immunocompetent Host. Journal Clinical Microbiology 43: 1002-1004, 2005.

7. Rabagliati BR, Morales SA, Baudrand BR, Jorquera JA, Oddó DB, Garcia PC, Carmona MCP, Cisternas MM, Huete AG. Neumonía cavitada por Rhodococcus equi em paciente inmunocomprometido no infectado por vírus de inmunodeficiencia humana. Caso clínico y revisión. Revista Chilena de Infetologia 22: 155-160, 2005

8. Sellon DC, Besser TE, Vivrette SL, McConnico RS Comparison of nucleic acid amplification, serology, and microbiologic culture for diagnosis of Rhodococcus equi pneumonia in foals. Journal Clinical Microbiology 39:1289-1293, 2001.

9. Severo LC, Ritter P, Petrillo VF, Dias CAG, Porto NS. Infecção pulmonar por Rhodococcus equi: relato dos dois primeiros casos brasileiros. Jornal de Pneumologia 27:158-162, 2001.

10. Tortosa-Torres M, Arrizabalaga, J, Villanueva JL, Gálvez J, Leyes M, Valencia E, Flores J, Peña JM, Pérez-Cecilia E, Quereda C. Prognosis and Clinical Evaluation of infection caused by Rhodococcus equi in HIVinfected patients. Chest 123:1970-1976, 2003. 